\section{Thieves of the state and the South African Medical Association (SAMA)}

'SAMA upholds the principles of honesty, integrity and patientcentredness and does not condone any unethical practice by its members. ${ }^{[1]}$

This is reassuring to see in print, even though it should go without saying for a nation's official medical association. The same SAMA mass e-mail's strident objection to the Free State government's withdrawal of approval for RWOPS (Remuneration for Work Outside the Public Service) during office hours is therefore rather surprising. Surely the very principle of RWOPS is that the work is pursued outside of office hours?

The fact is that doctors who do RWOPS are full-time state employees, and their primary obligation is to patients who use public medical services. It is therefore sheer hypocrisy to wail loudly about 'a threat to [private] patients relying on the services of these doctors' when it is public sector patients whose care is sadly compromised by RWOPS during office hours. All these doctors would need to do is to re-book their private patients for after-office-hours appointments.

The Medigram refers to the part-time private group practice in which they participate. The problem is that there are full-time state employees, some at senior consultant level, who run full-on single-handed private practices, complete with medical aid payouts and practice numbers. They are not just moonlighting, they are daylighting too, and these are not 'blanket allegations. ${ }^{\text {[1] }}$

Nice to know that, according to the e-mail, such thieves of the state ${ }^{[2,3]}$ do not exist in the Free State, ${ }^{[1]}$ but SAMA also 'acknowledged that the recently highlighted abuse of RWOPS by some in other provinces is recognised and is not acceptable. ${ }^{[1]}$ Yes, indeed. One is not expecting SAMA to be at the beck and call of the national Minister of Health. However, when he is quoted in our official journal as saying: 'Patients are actually dying because of specialist greed ... high mortality rates at certain hospitals correlate alarmingly with high RWOPS abuse ... would 'far rather' struggle to fill specialist vacancies caused by a clampdown on RWOPS than employ 'dishonest professionals who are never there anyway' ... here you have professionals stealing from the public and the nation ... ${ }^{[[4]}$ - then the Association needs to sit up and take notice.

Yes, SAMA is our trade union, albeit half-baked because of current legislation; and yes, it can and should defend its members well in industrial relations matters. Primarily however, a medical association is the mouthpiece of the medical profession in that country, its opinion available to the rest of the world.

SAMA may need the wisdom of Solomon in this matter to show that it is acting in the best interests of healthcare in South Africa. At the moment it does not seem to have applied too much thought, proactiveness or responsibility to the larger implications of this awful blot on our medical landscape.

\section{Robert Ian Caldwell}

Hilton, KwaZulu-Natal, South Africa

ric@caldwells.co.za

1. Patient care threatened by Free State doctor ban. SAMA Med-e-Mail, Vol. 08, No. 212.

2. Goldstein L. Thieves of the state. S Afr Med J 2012;102(9):719. [http://dx.doi.org/10.7196/SAMJ.6165] 3. Caldwell R. Thieves of the state - a response. S Afr Med J 2012;102(10):775. [http://dx.doi.org/10.7196/ SAMJ.6301]

4. Bateman C. Izindaba: RWOPS abuse - Government's had enough. S Afr Med J 2012;102(12):899-901. [http://dx.doi.org/10.7196/SAM].6481]

The South African Medical Association responds: SAMA agrees with some of the points made above. However, we note that Dr Caldwell, as most would do, acknowledges the complexity of the RWOPS issue. It is important not to become emotional about it, as people have tended to. Furthermore, a critical factor is to unpack and clearly delineate the issues around RWOPS so that the matter can be debated rationally. We remind readers that SAMA has a registered trade union that represents its public sector and employed doctors, and any assertion that such a trade union is 'half-baked' is unfair. Primarily SAMA exists to represent its members, who in turn are inextricably linked to the health and welfare of patients.

RWOPS was reached through a negotiated agreement, done nationally, and followed on the policy of 'limited private practice. The reasons for a RWOPS policy were part of a broad retention of skills strategy, which extended beyond just medical doctors. To do as the Free State and KwaZulu-Natal provinces have done and unilaterally cancel the agreement can never be acceptable. If this is how agreements are dealt with today, tomorrow other agreements can be unilaterally terminated by provinces without due process. As most would agree, this can never be the norm. If agreements need to be terminated or altered, this must be done through proper engagement and negotiation. To do otherwise sets a dangerous precedent, and SAMA will defend any agreements that have been achieved through negotiation.

A reason often cited against the continuation of RWOPS is the introduction of the Occupation-Specific Dispensation (OSD) for medical staff in 2009. It is very important to remember that the OSD did not adequately address the needs of specialists and higher-grade medical officers. More importantly, proper placement of people in correct job categories, e.g. head of a clinical unit, despite their doing the work that is required of that job, has not occurred in many provinces. Four years after the OSD, these issues therefore remain and have created much unhappiness. Given these facts, the retention objective of the OSD has not been met and RWOPS remains a reasonable model through which to achieve it. This can only be accomplished if the model as it currently functions is properly managed with effective oversight to root out any abuse that may occur.

SAMA can never condone the reported alleged abuse of RWOPS, but any unilateral action to stop the policy can equally not be tolerated. The policy had a purpose - the retention of specialist skills in the public sector. Unilateral action without addressing the core problem, viz. skills retention, will not serve any purpose; it is likely only to aggravate an already difficult situation.

Finally, SAMA remains deeply concerned about the sensationalist way in which the media and government alike are dealing with this matter. Generalisations are being made and doctors are being vilified by forensic reports without the courtesy of engaging with or informing SAMA. Equally, if high-ranking officials and MECs were willing to subject themselves to an audit of companies they own, the label 'thieves of the state' would perhaps need to be shared. Until such time, it is important that we deal with this matter rationally.

\section{Grootboom \\ M Sonderup \\ P Ramathuba \\ South African Medical Association \\ msonderup@samedical.co.za}

S Afr Med J 2013;103(6):354. DOI:10.7196/SAMJ.7008 